\title{
Correction to: Assisted reproductive technologies (ART) and childhood cancer: is the risk real?
}

\author{
Paolo Emanuele Levi-Setti ${ }^{1}$ (D) Pasquale Patrizio ${ }^{1,2}$
}

Published online: 25 October 2018

(C) Springer Science+Business Media, LLC, part of Springer Nature 2018

\section{Correction to: Journal of Assisted Reproduction and}

Genetics (2018) 35:1773-1775

https://doi.org/10.1007//10815-018-1274-6

The original version of this article unfortunately contained a mistake in the first sentence of the first paragraph in page 2. The sentence "In 2016, the Norwegian Register of births published a cohort study on all births occurred between 1984 and 2011 linking them with the Norwegian cancer registry data." should be "In 2016, Reigstad MM et al. [7] published a cohort study on all births occurred between 1984 and 2011 linking them with the Norwegian cancer registry data."

\section{Reference}

7. Reigstad MM, Larsen IK, Myklebust T, Robsahm TE, Oldereid NB, Brinton LA, et al. Risk of cancer in children conceived by assisted reproductive technology. Pediatrics. 2016;137:e20152061.

The online version of the original article can be found at https://doi.org/ 10.1007/s10815-018-1274-6

Paolo Emanuele Levi-Setti

paolo.levi_setti@humanitas.it

1 Humanitas Fertility Center, Rozzano, Milan, Italy

2 Yale Fertility Center, New Haven, CT 06511, USA 